\title{
Review of autologous blood transfusion at the Kenyatta National Hospital
}

\author{
G.O. Afulo, MBChB (UoN), MMed (Surg), Hand and Orthopaedic Surgeon, Kenyatta National Hospital \\ P.O. Box 20723-00202, Nairobi, Kenya
}

\begin{abstract}
Objective: This study was performed over a three- month period to establish the pattern of autologous blood transfusion with specific focus on age, sex, type of surgery, duration of hospital stay and religious beliefs.

Design: Hospital based prospective study.

Setting:The study was conducted at the Kenyatta National Hospital orthopaedic and general surgery wards. It involved in-patients who were admitted for elective surgeries.
\end{abstract}

Subjects: Sixty two patients were selected over a three-month period between October and December 2006 both months inclusive.

Outcome mesures: The inclusion criteria involved all male and female patients aged between 16-65 years. The pre-operative haemogram level ranged between 11-18 gm\% both inclusive. Exclusion criteria involved emergency surgeries, ages outside 16-65 years, haemogram level outside 11-18gm\%, and chronic medical illnesses. The sample size referred to the number of patients recruited during the study period and met the study criteria. Statistical analysis was performed using the appropriate statistical methods.

Results: Male: female ratio was 6:1. Age group was dominated by middle age group of 35-49 years. Religious distribution was Christians: non-christians in the ratio of 10:1.Surgeries performed were orthopaedics (78\%) and non-orthopaedic cases( $22 \%$ ). Duration of hospital stay ranged between 5-21 days.

Conclusion: Autologous blood transfusion is a common and safe mode of blood transfusion in surgery. It is more commonly practiced in orthopaedic surgery and needs to be encouraged among other surgical disciplines.

\section{LITERATURE REVIEW}

Autologous blood transfusion refers to transfusion of blood and/or blood components that are donated by the intended recipient (1). It is considered as one of the safest methods of blood transfusion $(1,2)$. Different types of autologous blood include: preoperative blood deposit, preoperative haemodilution,intraope rative salvage, postoperative salvage and speculative predeposit (1).

Up to four units of blood can be collected at weekly intervals and stored at $4-6^{\circ} \mathrm{C}$ (3). Older donated units can be retransfused as fresh units are collected (4-6).

In autotransfusion, the standard eight weeks interval between phlebotomies as practiced in homologous transfusion is eliminated (7). Donations are often scheduled weekly with the last phlebotomy performed 72 hours before surgery $(8,9)$. Autologous fibrin glue prepared from cryoprecipitate portion of plasma is used in achieving haemostasis (10-17). Fibrin glue may cause severe hypotension due to allergic reactions caused by systemically absorbed bovine thrombin (18). Autologous platelet rich plasma is used during heparin reversal in open heart surgery (19-24).

Most autologous blood deposit programmes require haemoglobin levels above $11 \mathrm{gm} / \mathrm{dl}$ before each phlebotomy and oral iron supplements are administered daily (25-28). Iron supplements are effective in supporting extensive phlebotomy but requires a longer period of time to be effective (29). During phlebotomy, erythropoietin level hardly rises above normal since the haematocrit level hardly falls below $30 \%(30,31)$.

The shortcomings associated with autotransfusion include: anaemia,hypovolaemia, sepsis from contamination, transfusion reaction due to wrong 
labeling, blood wastage due to delayed or cancelled surgery $(1,4,32)$.

The limitations associated with autotransfusion include: active septicaemia, chronic medical illnesses, haemoglobin level over $18 \mathrm{gm} / \mathrm{dl}$ and below $11 \mathrm{gm} / \mathrm{dl}$ among others (33).

Autologous transfusion requires close corporation between surgeons, anaesthetists, haematologists and other blood bank staff $(34,35)$.

\section{MATERIALS AND METHODS}

A total of 62 patients were recruited into the study. Inclusion criteria included all conscenting patients aged 16-65 years admitted for elective surgery with haemoglobin level of 11-18 gm/dl both sexes included.

Exclusion criteria involved all patients admitted for emergency surgery with age groups and haemoglobin levels outside the above figures and with chronic medical illnesses.

Sample size: This was equivalent to the number of patients recruited during the study period and meet the study criteria.

Data collection: The data was collected using a questionnaire which involved history taking, physical examination, laboratory and radiological investigations.

Data analysis: The study results were analyzed using appropriate statistical methods such as $\mathrm{Chi}$-Square and Students T test.

Study methodology: Patients were recruited from elective theatre lists of the respective wards. They were assessed and a questionnaire proforma was completed. The ages, sex, occupation, religion, diagnosis, planned surgery, laboratory and radiological results and duration of hospital stay were recorded. Most patients received their blood intraoperatively. All the above information was tabulated in form of bar-charts.

The data was compared with other studies elsewhere and the results were noted to be comparable when subjected to the $C h i-S q u a r e ~\left(X^{2}\right)$ and the Student T test.

\section{RESULTS}

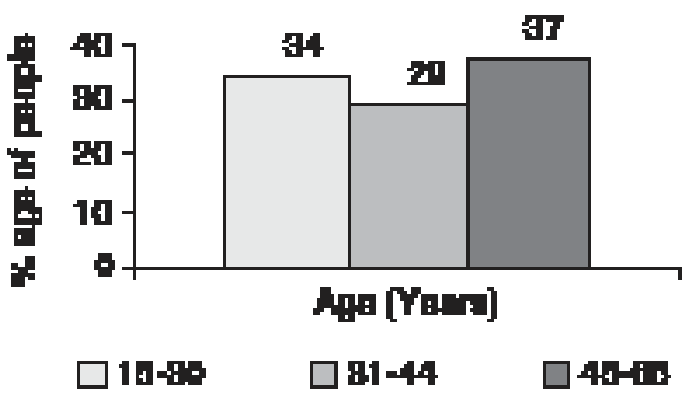

Figure 1: The distribution of patients according to age groups.

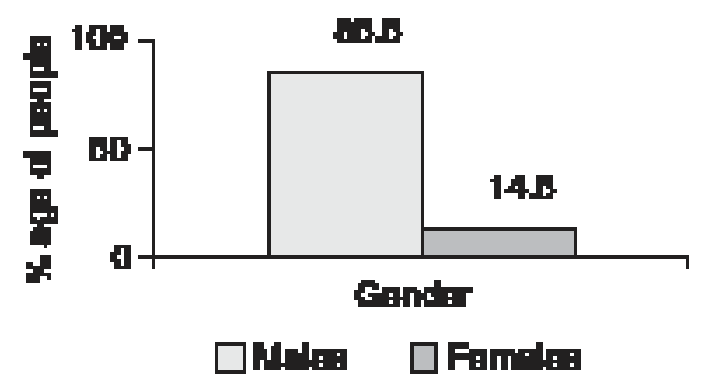

Figure 2: The study population in terms of sex distribution.

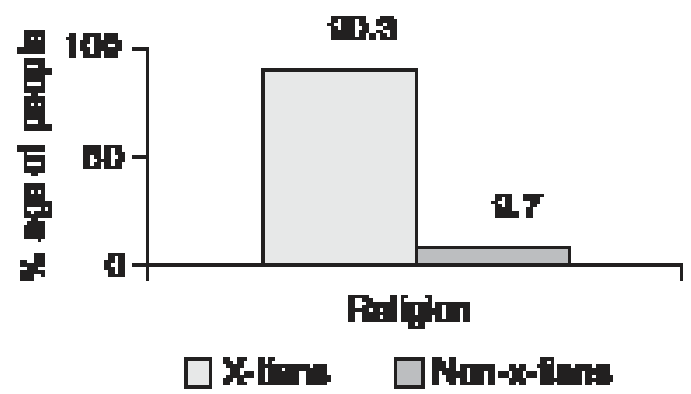

Figure 3: The distribution of the study population in terms of religion.

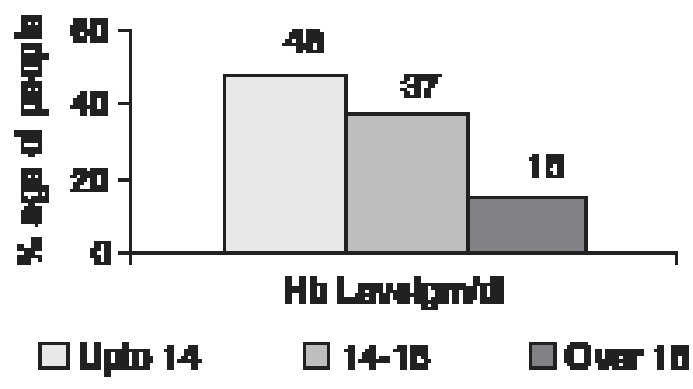

Figure 4: The distribution in terms of preoperative level of haemoglobin. 


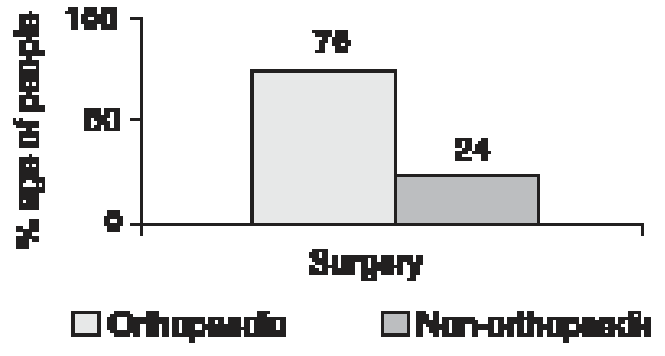

Figure 5: The distribution of patients according to surgery performed in the study population.

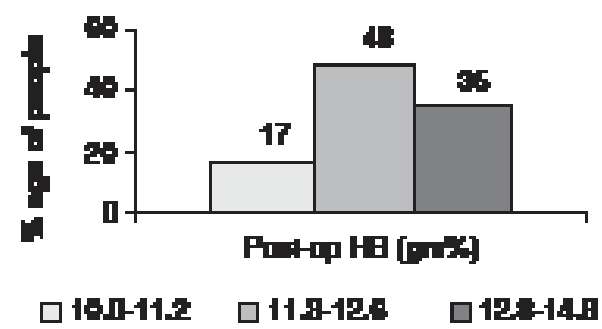

Figure 6: Distribution of patients according to the post operative haemoglobin level.

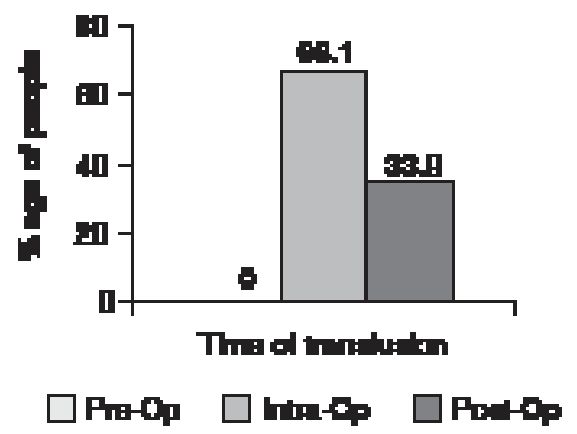

Figure 7: Distribution of patients according to time of transfusion.

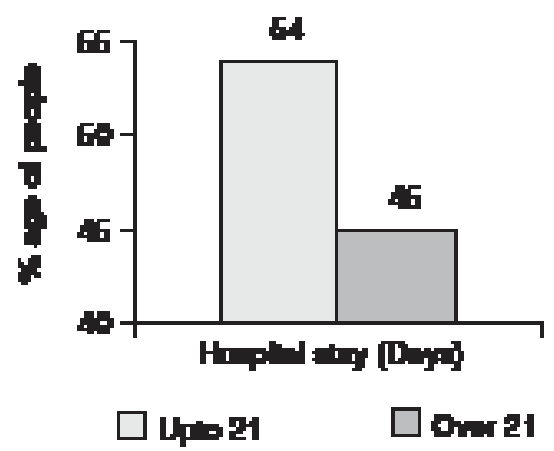

Figure 8: Distribution of patients according to the duration of hospital stay

\section{DISCUSSION}

In this hospital based prospective study, the pattern of autotransfusion was assessed.
The age group was dominated by middle aged population of 45-49 years. This is the most active and productive age group, which is much more exposed to occupational hazards and motor vehicle accidents (Figure 1).

The predominance of males over females in the ratio of $6: 1$ is relevant since males are more involved in rigorous activities of daily living and therefore more exposed to accidents of various varieties (Figure 2).

The distribution of patients in terms of religion was 10:1 for Christians and non-Christians respectively. This was due to the fact that Christians predominantly occupy the study area. Had the study been conducted in the coastal and/or north eastern regions of Kenya, the results could have been different (Figure 3 ).

The peak preoperative haemoglobin range was $13.4-14.2 \mathrm{gm} \%$ in both sexes. This is attributable to the fact that most of the patients were initially actively involved in their daily routines before they got injured (Figure 4).

The surgical procedures performed during the study period was predominated by orthopaedic cases (78\%) compared to non-orthopaedic ones who had some other co-morbid conditions (Figure 5).

Following the surgical procedures, all the patients had a post-operative haemoglobin level checked on the $3^{\text {rd }}$ day. None of the patients had a level below $10 \mathrm{gm} \%$, the peak being $11.3-12.6 \mathrm{gm} \%$ (46.8\%).The reduced haemoglobin level was due to intraoperative bleeding which was minimal (Figure 6).

The time of transfusion was mainly intra-operative (66.1\%).The timing was determined by the anaesthetist and the duration of the operation.A few patients (33.9\%) were transfused postoperatively.Most of these patients demanded their donated blood back after surgery even though they did not need to be transfused (Figure 7).

The peak duration of hospital stay was in the range of up to 5-21 days (Figure 8). This was dependent on the type of surgery, multiplicity of injuries and the postoperative state of the patient. The ones who stayed longest were mainly general surgical cases who developed post operative complications like wound sepsis among others.

\section{CONCLUSION}

Autotransfusion is a popular mode of blood transfusion globally. In Kenyatta National Hospital, it is more commonly practiced among orthopaedic patients. There is therefore need to encourage other specialties to make use of the method so as to lessen high demand 
for homologous blood. This will help the various institutions save a lot of resources in terms of manpower and financial allocation for purchase of reagents for screening of blood among other basic activities required to make homologous blood safe.

\section{REFERENCES}

1. Autologous Transfusion. American Association of Blood Banks. AABB 1990; 10th Edition pg 433-448.

2. Yomtovian R. Practical aspects of preoperative autologous transfusion. Amer. Med. J. Clin. Pathol. (United States). 1997; 107(4 Suppl 1): 28-35.

3. Wasman J. and Goodnough L.T. Autologous blood donation for elective surgery. Effect on physician transfusion behavior. JAMA. 1987; 258: 3135-3137.

4. Lee D. and Napier J.A.P. Autologous transfusion. Brit. Med. J. 1990; 300: 734-740.

5. Toy P.T.C.Y., Srauss R.G., et al. Predeposit autologous blood for elective surgery. New Engl. J. Med. 1987; 316: 517-520.

6. Per-Anders F. and David B. Possible benefits of preoperative blood deposit s for abdominal surgery. World J. Surg. 1997; 21: 349-352.

7. Mc Mahon A.J. And Mc Commick J.S. Combined predeposit and salvage auto-transfusion in elective aortic aneurysm repair. J. Royal Coll. Surg. Edinburgh. 1993; 38(2): 71-74.

8. Mintz P. Autologous transfusion endorsed. JAMA. 1985; 254: 507.

9. Campbell S. (ed). AABB goes public to fight donor fear of AIDS. Blood shortages. AABB News Briefs 1986; 1-4.

10. Consensus Conference. Fresh-frozen plasma. Indications and risks. JAMA. 1985; 253: 551.

11. Mathew T.I., Spotnitz W.D., et al. Four years experience with fibrin sealant in thoracic and cardiovascular surgery. Ann. Thorac. Surg. 1990; 50: 40.

12. Silberstein L.E., Williams L.J., et al. An autologous fibrin based adhesive for use in otologic surgery. Transfusion. 1988; 28: 319.

13. Stechison M.T. Rapid polymerizing fibrin glue from autologous or single donor blood. Preparation and indications. J. Neurosurg. 1993; 76: 627.

14. Dahlstrm K.K., Weis-Fogh U.S., et al. The use of autologous fibrin adhesive in skin transplantation. Plast. Reconstr. Surg. 1992; 89: 968.

15. Abel M.E., Chui Y.S., Russell T.R., et al. Autologous fibrin glue in the treatment of rectovaginal and complex fistulae. Dis. Colon Rectum. 1993; 36: 447.

16. Kram H.B., Clark S.R., Ocampo H.P., et al. Fibrin glue sealing of pancreatic injuries, resections and anastomoses. Amer. Med. J. Surg. 1991; 161: 479.

17. Dulchavsky S.A., Geller E.R., et al. Autologous fibrin gel; bactericidal properties in contaminated hepatic injury. J. Trauma. 1991; 31: 408.
18. Berguer R., Staerkel R.L., et al. Warning: Fatal reactions to the use of fibrin glue in deep hepatic wounds. Case report. J. Trauma. 1991; 31: 408.

19. Giordano G.F., Rivers S.L., et al. Autologous platelet-rich plasma in cardiac surgery; effect on intra-operative and postoperative transfusion requirements. Ann. Thorac. Surg. 1988; 46: 416.

20. Harker L.A., Malpass T.W., et al. Mechanism of abdominal bleeding in patients undergoing cardiopulmonary bypass: Acquired transient platelet dysfunction associated with alpha granule release. Blood. 1980; 56: 824.

21. Boldt J., Von Bormann B., et al. Pre-operative plasmapheresis in patients undergoing cardiac surgery procedures. Anesthesiology. 1990; 72: 282.

22. Davies G.G., Wells D.G., et al. Platelet-leukocyte plasmapheresis attenuates the deleterious effects of cardiopulmonary bypass. Ann. Thorac. Surg. 1992; 53: 274.

23. Delrossi A.J., Cernaianu A.C., et al. Platelet-rich plasma reduces postoperative blood loss after cardio-pulmonary bypass. J. Thorac. Cardiovasc. Surg. 1990; 100: 281.

24. Wickey G.S., Keifer J.C., et al. Heparin resistance after intraoperative platelet-rich plasma harvesting. J. Thorac. Cardiovasc. Surg. 1992; 103: 1172.

25. Council of Scientific Affairs. Autologous blood transfusions. JAMA. 1986; 256: 2378-2380.

26. Sandler S.G. and Silvergleid A.J. Autologous transfusion. Arlington, VA, AABB. 1983.

27. Mann M., Sacks H.J., et al. Safety of autologous blood transfusion prior to elective surgery for a variety of high risk patients. Transfusions. 1983; 23: 229-232.

28. Miles G., Browne W.H., et al. Autologous transfusion for elective Caeserian section. Amer. J. Obstet. Gynacol. 1969; 103: 1166-1167.

29. Finch C.A., Cook D.J. and Labbe R.F. Effects of blood donation on iron stores as evaluated by serum ferritin. Blood. 1997; 50: 441-448.

30. Kickler T.S. and Spivak J.L. Effects of repeated whole blood donations on serum immunoreactive erythropoietin levels in autologous donors. JAMA. 1988; 260: 65.

31. Goodnough L.T., Rudnick S., et al. Increased pre-operative collection of autologous blood with recombinant human erythropoietin: A controlled trial. N. Engl. J. Med. 1989; 321: 1163.

32. Cousin M.T., et al. Effects of autologous and homologous transfusions (FRENCH) on bacterial infection after heart surgery under extracorporeal circulation. Ann. Surg. 1994; 48(9): 818-824.

33. Greenwalt T.J. Autologous and aged blood donors. JAMA. 1987; 257: 1220-1221.

34. Cooley D.A. Conservation of blood during cardiovascular surgery. Amer. J. Surg. 1995; 170(6A suppl): 53s-59s.

35. Mercuriali F., et al. Auto-transfusion programme; Integrated use of different techniques. Int. J. Artificial Organs. 1993; 16(suppl 5): 233-240. 